\title{
The Incentives of Wind Power Production and Inte- gration in US Policy
}

\author{
By Samuel S. Webster
}

This paper analyzes the impact of the federal Production Tax Credit on the development of wind energy in the US. Following an analysis of the incentives these policies produce for wind energy generation and integration, this paper finds that, although the Production Tax Credit has proven effective at promoting some level of wind power development, the effectiveness of the Production Tax Credit varies by region and by itself is unlikely to achieve the deep levels of wind power penetration desired by some policymakers and the U.S. Department of Energy.

\section{Introduction}

Originally enacted in the Energy

Policy Act of 1992 (Pubic Law No. 102486), the Production Tax Credit (PTC) supplies a tax incentive for every kilowatthour (KWh) of qualifying renewable energy produced by projects over a certain size during the first ten years of their operations. When the PTC was set to expire at the end of 2012, Congress and interested stakeholders engaged in a discussion about the role of government in the energy sector and whether or not policies should support renewable energy like wind. While the debate generated a number of arguments, at its heart it was a disagreement between interest groups that saw the PTC as an unreasonable expense or unwelcome help for a competitor and wind developers and environmentalists who saw it as key to continued wind power growth in the US. However, this discussion tends to over- look key factors contributing to renewable energy generation levels, including electric grid stability, efficiency, and the possibility of integrating renewable power onto the grid. Without these considerations, discussions of renewable energy subsidies miss important facts that are crucial to generating effective public policy.

This paper will investigate the economic incentives produced by the PTC and other US wind energy policies and explore the effect these policies have on the expansion of wind power in the US. The focus will be primarily on how subsidies affect incentives to integrate wind power with the electric grid since this is a key topic in renewable energy that is often not adequately addressed. Section one will provide a basic introduction to the organization and operation of the US energy grid. It is important to understand the economic issues inherent in grid management, as well as some of the grid's physical constraints, in order to properly understand the role subsidies play in integrating new power sources. Section two will provide background on current US policies and subsidies towards renewable energy. This section will include a brief primer on levelized costs of energy production (costs that take into account capital, fuel, dispatchability, and other factors) and the competitiveness of wind with fossil fuels. Section three will discuss the incentives generated by these policies and how they effect wind energy penetration into the US market, construction of new wind energy 
installations, and the overall share of the market controlled by wind. Section four will discuss options for improving wind integration and provide avenues of possible research and discussion.

There is not agreement on whether increasing wind power usage is a normative good and whether the government should have any role in the sector. This paper is not concerned with the normative value of wind power and will focus exclusively on whether or not current subsidies are a useful way of increasing wind penetration, if that is to be a policy goal.

\section{Section One: The Electrical Grid}

Physically, the US energy grid is divided into three regional transmission networks: the Western Interconnection, the Eastern Interconnection, and the Electric Reliability Council of Texas (Burnage 2009). Within these interconnections, power is transmitted by regional transmission organizations (RTOs) and independent systems operators (ISOs). Electricity within regions is most commonly provided by varying sizes of alternating current (AC) lines due to their larger capacities relative to their direct current (DC) counterparts.
The regions are connected to each other by DC lines, which are cheaper to construct over longer distances and incur less power loss but which have lower capacities than AC lines. Each region provides the majority of its own power, which is distributed by the AC lines and normally turns to the DC interchanges for emergency power during power shortages or outages (Lerner 2003).

The physical limitations of the grid are important since they affect the incentives of the independent power providers, who generate the power and own the generators, and the transmission companies, who operate the transmission equipment. One constraint of the grid is that transmission lines must operate beneath capacity since the grid is designed to adapt to changing demand for electricity, such as when demand spikes in some areas or if lines experience failures. If the grid is operating too close to maximum capacity, it can cause point failures that have triggered a series of cascading failures and blackouts (NYISO 2005).

A second constraint is that power is not normally transferred between regions of the country, which would be very long distance, but rather, generated closer

Figure 1. Electric Transmission by Voltage Class

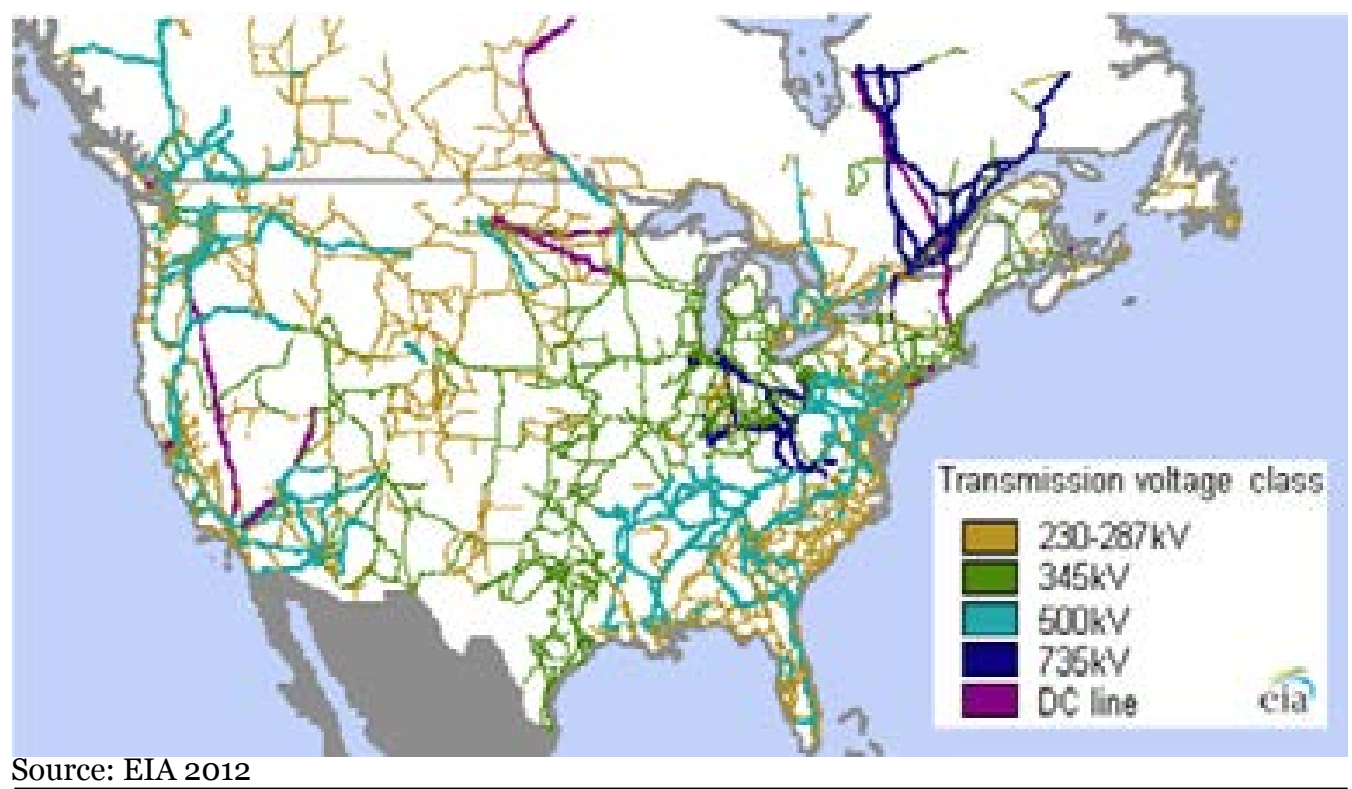


to the area in which it is used. Power is only transferred between regions in the case of failures or extremely high demand (Lerner 2003), and there are no interconnections with Electric Reliability Council of Texas.

These physical constraints are important when assessing the incentives produced by energy subsidies and possible solutions to shortcomings of the energy grid. Figure 1 demonstrates the complexities of this grid.

The reason the physical concerns of the grid are important to any discussion of energy incentives is because grid economics are often a function of grid physics and the resulting supply delivery bottlenecks it causes. While the grid was originally treated as a public good with centralized generation and distribution, it underwent massive changes when the Energy Policy Act of 1992 deregulated the sector by allowing unbundling power generation and power transmission, which split duties for generating, transmitting, and distributing power to different entities. These trends were codified by a series of regulations issued by the Federal Energy Regulatory Commission (FERC), notably Orders No. 888 and 889, issued in April 1996, which required that power transmission companies transmit the power of independent generation companies as they would their own (Lerner 2003). FERC orders were designed to increase competition in power generation.

\section{Section Two: Current US and State Policies}

In addition to a basic understanding of the grid, it is also important to be familiar with current energy policies. Over the past two decades, policies enacted at the federal and state levels have put a significant policy emphasis on increasing the percentage of energy that is produced from renewable sources (DOE 2013). The increase in wind penetration has been driven by tools such as government investment in research and technology, tax credits for production, investment and manufacturing; and mandates or goals instituted at the state level to produce a certain percentage of all energy from alternatives sources,

Figure 2. Levelized Cost of Electricity Across Power Generation Technologies: 2013, 4th Quarter (2009\$/MWh)

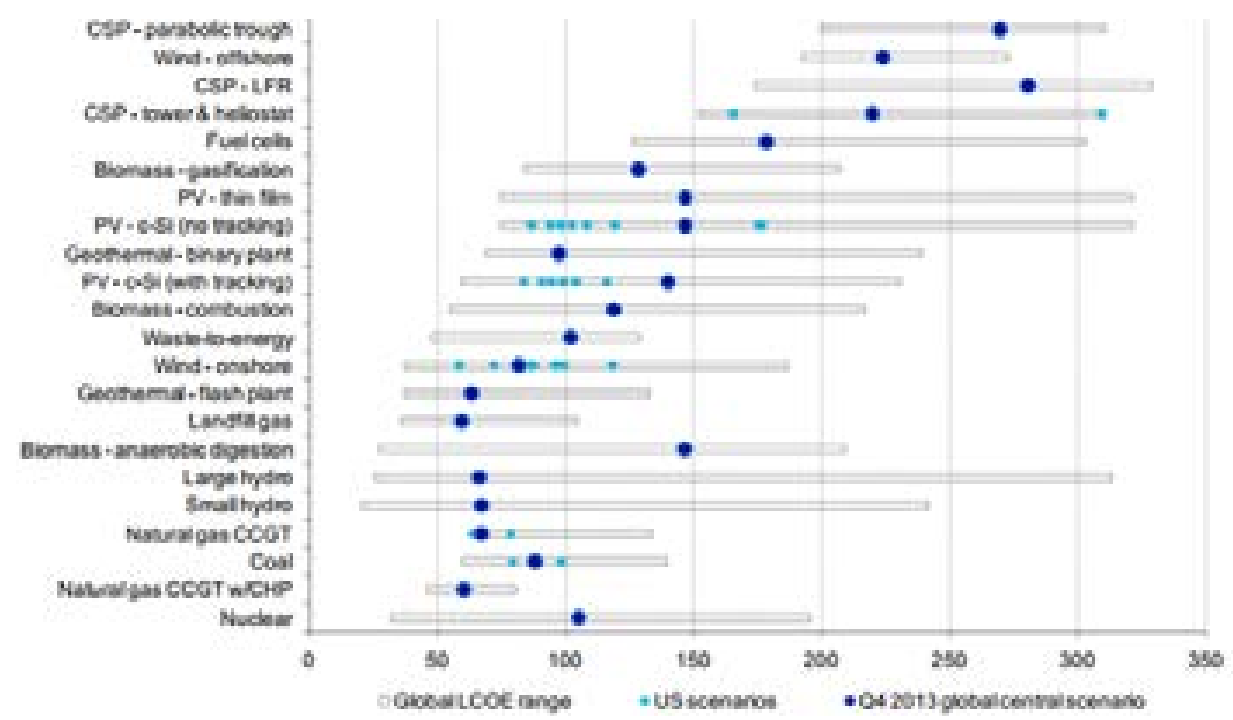

Source: Business Council for Sustainable Energy and Bloomberg Finance L.P. 2014 
usually renewables (most renewable portfolio standards do not require wind specifically, but it has historically been the most affordable alternative option). Most important for this analysis are the PTC and the renewable energy portfolio standards.

The PTC, enacted in 1992, has been consistently renewed every few years whenever it nears expiration, which has created a great deal of uncertainty for renewable energy markets since producers are unable to plan for the future. This resulting boom and bust cycle means that many installations are scheduled immediately before an expiration of the PTC and fall off dramatically the next year. The Union of Concerned Scientists claim installations drop between 76 and 93 percent after an expiration. This cycle can make the costs and the benefits of the PTC very difficult to determine.

The PTC was originally 1.5 cents per KWh of electricity produced by qualifying renewable sources including wind, geothermal, and closed-loop biomass for the first ten years of a plant's operation. However, adjusted for inflation, the PTC is now approximately 2.3 cents per kilowatt-hour KWh (DSIRE 2013). According to the American Wind Energy Association, wind power receives this credit in order to drive down the costs associated with erecting new turbines and to help make wind power competitive with traditional power sources (AWEA 2013). Growing capacity of wind power has increased the total cost of the PTC, and a one-year extension in 2014 was estimated to cost around $\$ 5$ billion (Styles 2013).

State-level renewable energy portfolio standards typically mandate that a certain amount of electricity consumed within a state must be derived by renewable means. This is not an attempt to correct for externalities, such as emissions from burning fossil fuels through market means (as a carbon tax would) or increase supply through market means (as does the PTC), but rather bypasses the mar- ket in order to mandate the use of power that does not have such externalities. The renewable portfolio standards have driven down prices of wind turbines by promoting increases in production but in some cases have resulted in unintended consequences.

\section{Section Three: Incentives, Com- mons, and Innovation}

As stated above, US and state efforts to improve wind penetration in the US market as of the end of 2013 have been mostly driven by incentives to increase production and to create new power installations, either by bringing down costs or through production mandates. The PTC expired at the end of 2013, although Congress added new provisions in 2012 allowing partially constructed wind farms to qualify for the credit after 2013. These efforts, however, have largely ignored the complications of distributing this power once it is produced and in doing so have produced unintended consequences and inefficient market behavior. This section will address three specific concerns: (1) that wind power might well be constructed in many regions in the absence of the PTC; (2) that FERC orders have the unintended consequence of disincentivizing grid expansion; and (3) that the PTC and renewable portfolio standards, as they are now, incentivize mature technology at the expense of developing technologies that would help the US reach its renewable energy targets. This latter point is a problem that goes far beyond wind, as fossil fuels are abundantly subsidized as well.

Production incentives attempt to reduce costs to competitive levels in order to bring wind power into the market. While not the case when the PTC was established in 1992, in some markets today, wind power is competitive with other technologies even in the absence of the PTC. Lazar (2013), for example, calculates that wind, under optimal conditions, can reach levelized costs of $\$ 45 /$ megawatthour (MWh) in the Midwest and \$51/ MWh in Texas. It is important to note that 
Table 1. Range for Total System Levelized Costs for Plants Entering Service in 2018 (2011\$/MWh)

\begin{tabular}{|l|l|l|l|}
\hline Plant type & Minimum & Average & Maximum \\
\hline Dispatchable Technologies & & & \\
\hline Conventional Coal & 89.5 & 100.1 & 118.3 \\
\hline Natural Gas-fired & & & \\
\hline Conventional Combined Cycle & 62.5 & 67.1 & 78.2 \\
\hline Advanced Combined Cycle & 60.0 & 65.6 & 76.1 \\
\hline Advanced Nuclear & 104.4 & 108.4 & 115.3 \\
\hline Non-Dispatchable Technologies & & & \\
\hline Wind & 73.5 & 86.6 & 99.8 \\
\hline Wind-Offshore & 183.0 & 221.5 & 294.7 \\
\hline
\end{tabular}

Source: EIA 2013

levelized cost calculations can be controversial and are sensitive to assumptions. The calculations below do not account for any subsidies (to either renewable or traditional sources), nor do they account for externalities such as carbon emissions, both of which would drastically change the estimates. They do attempt to account for intermittency, but the estimates used here can cause dramatic variation as well, and changing assumptions could certainly change these numbers.

The Business Council for Sustainable Energy and Bloomberg New Energy Finance's estimates of levelized costs, displayed in Figure 2, show wind to be relatively competitive with traditional power sources, though a range of scenarios show wide variability in costs.

The Energy Information Adinistration also produces an optimistic outlook for wind power's levelized costs, which is displayed in Table 1.

The OpenEI project (2013), which aggregates levelized cost estimates from published research, also produces numbers that predict the competitiveness of wind power. Figure 3 shows estimated levelized costs for 2011-2012 aggregated from numerous publicly cited studies between 2008 and 2012. This chart indicates onshore wind has a minimum levelized cost of $\$ 0.03 / \mathrm{kwh}$ and maximum of $\$ 0.09 / \mathrm{kwh}$, compared to a minimum of $\$ 0.03$ and maximum of $\$ 0.07$ for natural gas. Offshore wind's levelized costs were considerably higher.

These models are very sensitive to changing assumptions, and the costs presented here indicate that wind can very likely be competitive, at least in some markets. This is evident in Texas where from 2011-2012 there have been 1,842 megawatts (MW) of wind power installed, compared to $563 \mathrm{MW}$ for natural gas, according to the Public Utility Commission of Texas. Though the PTC certainly plays a role in this, it is difficult to know how much (PUCT 2013).

There are additional costs of integrating wind power into the electrical grid, but these costs are very difficult to account for and vary greatly based on region. PJM, which coordinates the transmission of wholesale electricity, cites integration charges from $\$ 3.60 / \mathrm{MWh}$ to $\$ 9.50 / \mathrm{MWh}$ that are being levied by some utilities (Porter et al. 2012). Accounting for these costs might make wind uncompetitive in certain regions, but would probably not be sufficient to make wind universally uncompetitive. These dynamics mean it is unlikely that the PTC (at least for onshore wind) can produce 
Figure 3. Estimated Levelized Costs Across Generation Resources Aggregated Between 2011-2012

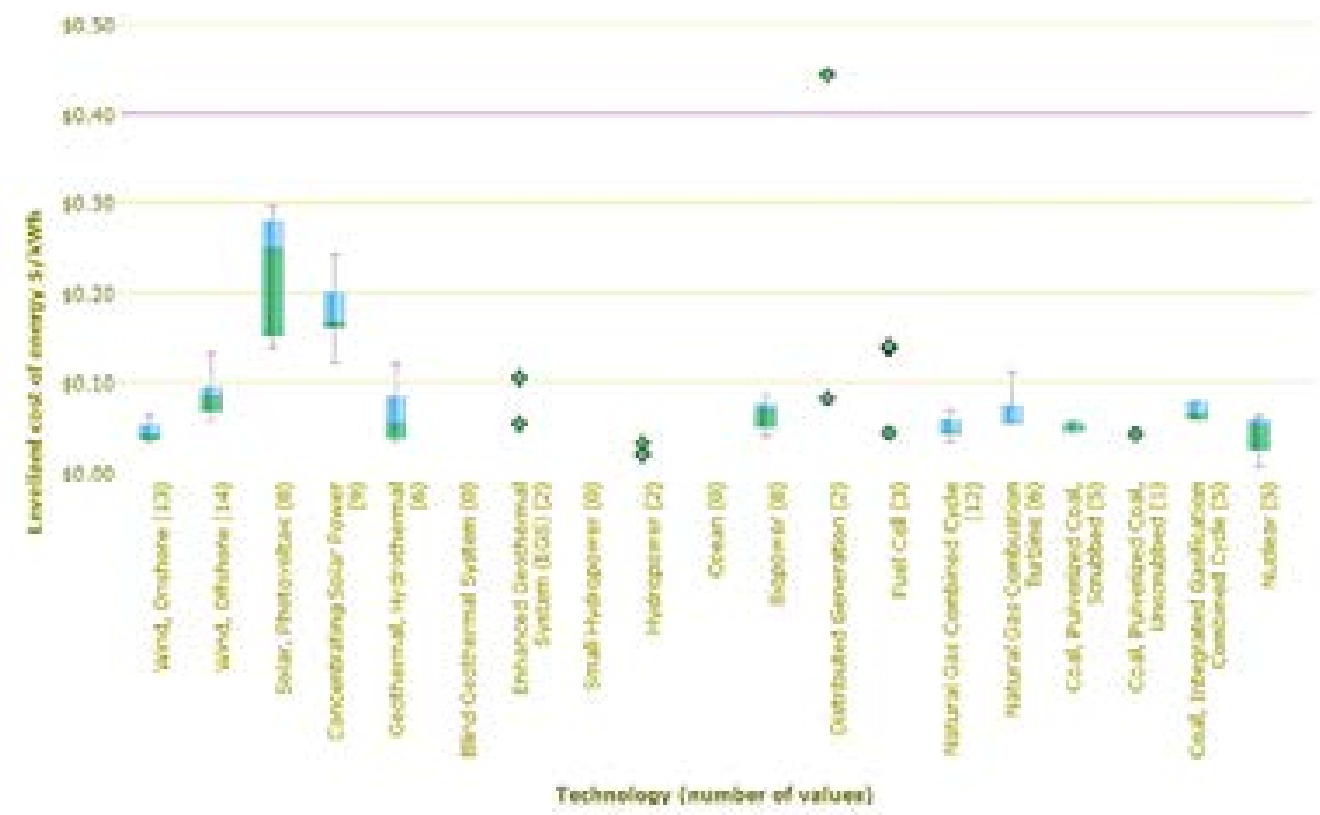

Source: OpenEI (2013)

the desired changes to the US energy mix that its authors intended.

What incentives then do the PTC and portfolio standards actually produce if wind is already, at least in some places, a competitive technology? Since production is subsidized (and mandated in the case of renewable portfolio standards), while transmission and distribution are usually not, one consequence is that wind power construction is primarily developed in areas well served by the existing grid. Areas where wind power is potentially abundant and could provide a larger amount of resources to the US, including much of the Midwest and offshore, have relatively few new generation facilities, and the grid has not been expanding to serve these areas. Historically, constructing new high-voltage transmission capacity has been difficult because of the large upfront capital required, the relatively low levels of return, and often fierce local opposition to new transmission lines. It may be understandable why developers are hesitant to build new lines and take risks on developing other areas when they have access to less risky profits, but subsidizing that behavior is not necessarily the best use of public funds. Better incentives for increasing the role of wind in US energy development might focus on subsidizing new transmission lines, where politically feasible, and targeting subsidies on less competitive technologies, such as offshore wind, which has abundant potential but cannot yet compete. Figure 4 shows wind resources available in the United States by region within the existing energy grid. Figure 5, in contrast, shows the existing transmission lines and wind power installations constructed before and after 2009.

The grid is most robust in areas where wind resources have not been heavily developed and, despite more than two decades of subsidies, there has been little expansion to cover these areas with high wind potential. This is evident in that wind generation facilities before 
and after 2009 have largely been constructed in the same locations and have not expanded into territory with more abundant wind. Given this, the PTC may no longer be the best way of incentivizing more wind penetration into the US energy mix.

Existing subsidies may make it easier to construct wind installations, but they seem to succeed primarily in incentivizing this construction in places where it would likely happen anyway, namely those areas where the grid can handle the extra power already and costs of construction are low-if wind is indeed competitive in these circumstances. Lazard (2013) shows that wind in the Midwest and in Texas is competitive with both natural gas and coal even without the PTC, though it is far from competitive in the Southwest, Southeast or Northeast (their analysis does not mention the Northwest or California). These regions are precisely where we see new construction.
Since construction is subsidized and fuel costs are functionally free, power providers take few risks on new turbines if they are already integrated or easily able to be integrated. Since they are subsidized to bring down their levelized costs, they can take market share from other power sources when bidding on the grid and be assured of a profit.

One example of how subsidies can skew behavior is the anomaly of negative price across parts of the Midwest and Northwest. On some occasions these negative prices have forced operators of other technologies to pay the grid to take their power if it cannot easily be shut off (Malik and Johnsson 2013). In contrast, wind power during low demand periods with negligible fuel costs has been able to bid negative amounts in competitive markets due to tax credits. As long as payment from the PTC and associated Renewable Energy Credits are more than the cost of selling electricity

Figure 4. Existing Wind Resources and Transmission Lines

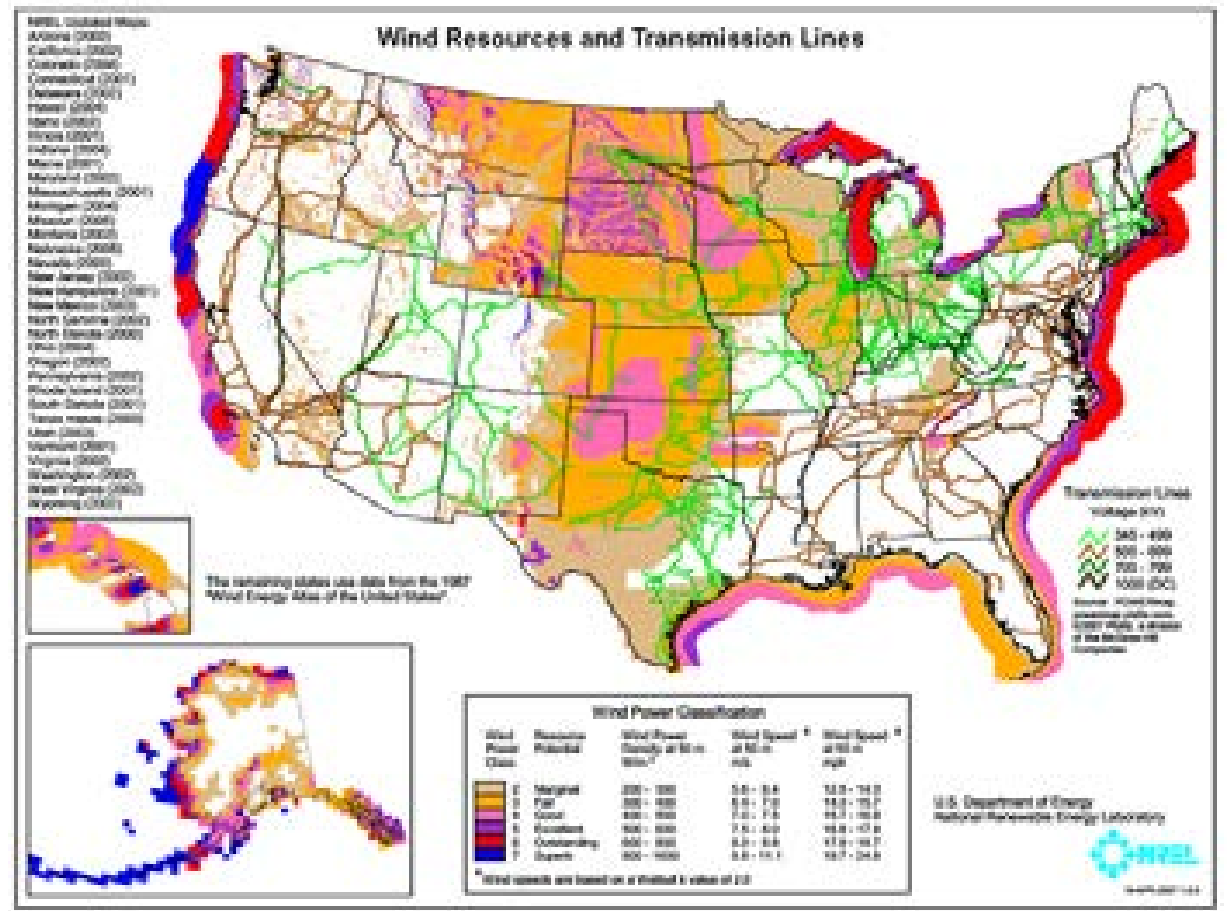

Source: NREL 2014 
Figure 5. Existing Transmission Lines and Wind Power: Pre- and Post-2009

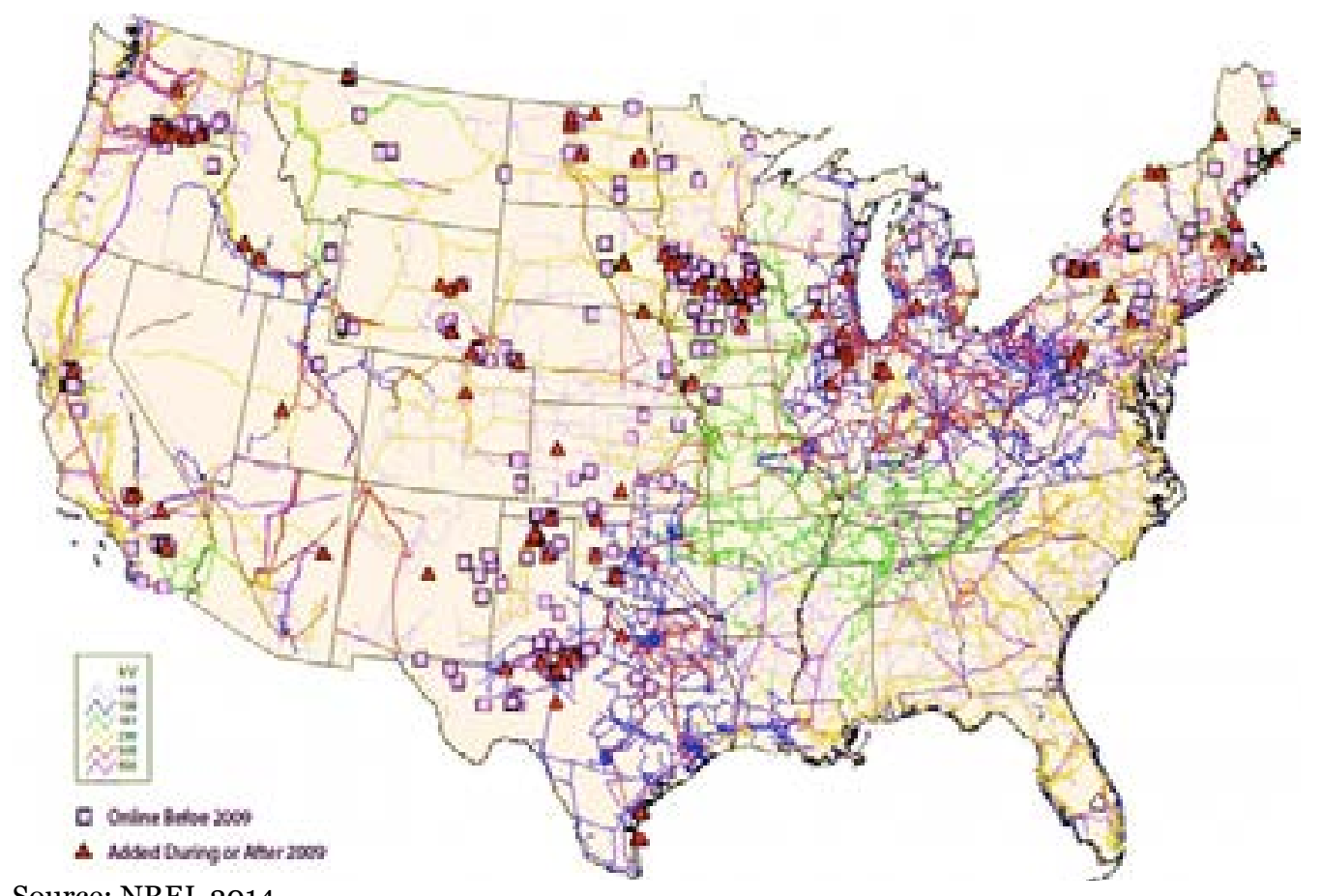

Source: NREL 2014

at the negative rate, producers who can take advantage of the tax credit can still make a profit.

The frequency of such occurrences varies greatly by region, but naturally they occur much more often in times of low demand and high wind output, and most frequently in Iowa and in West Texas. The Northbridge Group, which advises the natural gas industry, finds that throughout much of PJM, the percentage of hours with negative realtime electricity prices are in the fractions of a percent, but in northern Illinois hover closer to 2 percent and can reach 10 percent in other areas such as West Texas (Huntowski et al. 2012).

Other unpredictable situations also play roles in these anomalies, such as periods of incredibly low demand or high power output from other renewable sources such as hydroelectric. It is the PTC itself, however, which allows the sale of power to be profitable in negative price situations and gives wind operators little reason to build elsewhere, where investment incentives would still apply. Building in places where the grid must be expanded to reach therefore carries far more risk, even if it reduces the chances of these negative price anomalies. It is important to note that not all wind power subsidized by the PTC can result in these anomalies, but rather only once enough capacity has been installed. At high levels of congestion, these anomalies can result, and additional installed wind power becomes inefficient to the system. The PTC is a problem here because it is still worthwhile to the developer to install wind power, even if it is not worthwhile for the grid.

Some regions of the country are not currently cost-competitive for wind, because there is not enough consistent wind available. That may change as turbine prices continue to decline, turbines become more efficient at lower wind speeds, and the generation costs of their 
fossil fuel competitors increases. For now, neither the PTC nor any other subsidy will incentivize abundant wind power in these regions. Subsidies or regulations other than the PTC might produce better incentives, however, in areas where wind does have potential. If the production and investment tax credits were to focus on less competitive technologies such as offshore wind, this might help spur additional innovation. Government assistance in expanding the grid between regions and allowing sale of electricity across regional boundaries could also help encourage wind development in more remote areas and would benefit other technologies (such as utility-scale solar) as well. Such efforts would undoubtedly be politically difficult but would likely be more valuable than subsidizing development of a relatively mature technology in regions where it might already be competitive.

Beyond subsidizing energy that is potentially already competitive, a second issue emerges from FERC Order No. 888, which unbundled power generation and transmission. This order was given to increase competition in electricity generation by offering more providers access to the grid. Utilities had a practice of "goldplating" or overstating the cost of improvements in order to discourage service to new providers (FERC 1996). Order No. 888 allowed more providers onto the grid, potentially improving the overall US energy picture.

Order No. 888 also, according to Lerner (2003) and the utility executives he interviewed, disincentivized grid integration. In requiring transmission companies to treat the power generated by independent plants the same as the power generated by the transmission companies themselves, the law created a kind of tragedy of the commons.

Power producers have little incentive to concern themselves with grid expansion as the transmission lines are run by other companies who are obliged to take their power (2003). Grid expan- sion, assuming regulations would allow it to be traded across distances, would be in everyone's interest. Yet, after Order No. 888, parties found it difficult to raise funds to expand. Producers that could get their power to market and had subsidies that made it cheap to do so had little need to build in more wind-rich, but isolated areas, especially since expanding the grid introduces competitiveness and limits what incumbents can charge. These producers could perform just as well or better for a smaller fixed cost by generating as much power as possible in developed areas and using as much of the grid capacity as they could. This is because transmission companies are compelled to purchase their power if they are the lowest bidders in markets where price is determined by auction. Resources are often simply better spent producing subsidized electricity. It makes little economic sense to put money into a project such as the energy grid on which it is difficult to get a return when electricity is commoditized.

The physics of the grid exacerbate this problem. Since the grid must be run at lower than maximum capacity, all suppliers would prefer to use as much of that capacity as they are able. It is more cost effective to take market share from others, pushing them out of the grid rather than expanding the grid to benefit everyone. A 2008 New York Times article, aptly titled Wind Energy Bumps Into Power Grid's Limits, discusses particular instances of the system being glutted by power (Wald 2008). Often, however, since wind power is subsidized and its fuel is free (so the levelized cost function only needs to account for construction and maintenance), wind power will push traditional power sources off the grid (Malik and Johnsson 2013). Renewable energy standards encourage this as well by mandating that a certain amount of power come from renewable energy, which usually means wind, since it has historically been more competitive than solar. Though this can lead to an expan- 
sion in wind power (as in Iowa) and has had a role in driving down the costs of turbines through increased production, it also leads to states purchasing more costly wind power over traditional means and taking grid resources from other suppliers, rather than encouraging efficient or effective wind generation.

Replacing traditional power from fossil fuels with renewables is often the focus of renewable energy policy, so this redistribution might be beneficial, especially for those concerned with pollution externalities. In the broader sense of increasing wind penetration and power available to the US, however, this is inefficient when vast reserves of wind power remain untapped. This inefficiency is relevant as demand for electricity continues to grow, even though the rate of electricity growth has slowed drastically. The Annual Energy Outlook early release report for 2014 indicates electricity consumption will grow by about 29 percent between 2014 and 2040, or roughly one percent annually (EIA 2014).

Rather than expanding the country's energy resources, the combination of production tax credits, portfolio mandates, and a physically outdated and limited grid have produced a zero-sum game in which providers skirmish over grid access while leaving valuable resources undeveloped in order to optimize subsidies.

The answer is probably not to rescind Order No. 888 as advocated by Lerner (2013) and the utility executives he cites; however, given the likely bias of utility operators, their concerns about the physics of the grid being endangered by the new model are still not without merit. The answer lies more in developing and subsidizing capacity and infrastructure, not in rescinding an order geared towards increasing competition.

The third problem with current energy incentives is that they can hinder innovation. This paper has been focused fairly exclusively on wind, but this issue goes far beyond federal and state policies towards wind and encompasses shortcomings in energy policy as directed towards all forms of production. A report by the Brookings Institution observes,

Renewable portfolio stan-
dards, for example, which
require utilities to purchase a
certain percentage of elec-
tricity generation from re-
newable sources, encourage
deployment of the lowest-cost
renewable energy technology
available-generally wind
power or biomass" (Jenkins
et al. 2012).

The report focuses on how wind power hinders higher cost technologies such as solar, however, it is also true that advances in wind power are limited by the subsidies, since they eliminate some of the need to make wind power cheaper, more versatile, and more integrated.

Patrick Jenevein, CEO and

founder of several green energy companies, supports the Brookings report. He writes, "the industry produces a product that isn't as efficient or cheap as it might be if we focused less on working the political system and more on research and development" (Jenevein 2013). The Department of Energy (DOE) in its 2011 Wind Technologies Market Report acknowledges that,

[I]t is possible that developers have seized this limited opportunity [of the investment tax credit] to build out the less-energetic sites in their development pipelines. Additionally, state [renewable portfolio standards] requirements sometimes require or motivate in-state or in-region wind development in lower wind resource regimes. 
As wind power matures and becomes more competitive, there is some emerging consensus that it is possible that subsidies limit the need to expand wind power and increase innovation. This is certainly not a situation unique to wind power, however. Energy Incentives: The Power Behind the Power, a report by the George Washington University Solar Institute, details how long mature fossil fuel technologies have been subsidized for decades, a trend which continues today. The report shows that the average annual subsidy for oil and gas from 1918 to 2009 in 2010 dollars has been $\$ 4.86$ billion, compared to $\$ 0.37$ billion for renewables between 1994 and 2009 (Pfund 2011).

If subsidies have limited the advancement of wind or solar power, they have likely also reduced incentives for fossil fuels to become greener or more efficient. If true, this should be a wake-up call to eliminate subsidies for technologies that are mature and focus instead on bringing high potential, but currently uncompetitive technologies, such as offshore wind and solar, to the market.

\section{Section Four: Where Do We Go From Here?}

A full analysis of policy options would require a more advanced knowledge of grid physics and the interplay between different business entities involved in the grid than have been presented here and which are beyond the scope of this paper. However, it is appropriate to ask: how can wind energy incentives be made more efficient and effective when it comes to actually encouraging wind expansion?

The American Institute of Physics (AIP) has suggested repealing Order No. 888. What's Wrong with the Electric Grid? focuses more on how to prevent blackouts than on how to integrate the grid, but the results and methods are the same. Fundamentally, the Energy Policy Act of 1992 and Order No. 888 endeavored to make electricity into a commodity, while operating a grid that in many ways functions more like a public good. The AIP argues that repealing Order No. 888 would reduce the incentive to flood the grid with power that cannot be processed due to low demand or intermittency, both increasing grid stability and providing reasons to shift resources into expanding the grid and integrating other resources (Lerner 2003). AIP's recommendation would certainly result in a more stable grid and reduce the incentives to overload the system, but it is not at all clear that this effort would incentivize wind power (or other renewables) in any meaningful way. Repairing the physical problems may correct some of the economics, but it might also hinder competition in power markets, and if so, it would be a step backwards.

Some have called for expanded infrastructure in the place of subsidies (Gray 2012). The goal of expanding infrastructure would be to allow transmission of power across long distances, reducing the impact of the intermittency of wind and making more areas of the country viable for development, while providing incentives for technological innovation. DOE has put forth a similar proposal (DOE 2008). The DOE plan would also ensure that power could be sold and transmitted across regions, providing opportunities for regions rich in renewable energy sources to exploit them.

In its report, 20\% Wind Energy by 203O, DOE recommends more government investment in grid infrastructure funded by higher utility prices. Replacing subsidies with infrastructure investment would offer developers a reason to construct plants in undeveloped areas that nonetheless have high wind power potential instead of glutting some areas with overpriced and inefficient power. The concern with this approach is of course its cost.

DOE has estimated the transmission lines that would be required to reach 20 percent wind penetration by 2030 and analyzed how the cost of these new lines would increase wind prices in order to determine new levelized costs. Estimates for 
various expansion projects tended to hover around ten percent of the existing price per KWh, depreciated over 15 years. DOE's rough estimate gives wind power the best assumptions since it is unclear how much of the cost of new transmission would be borne by wind and how much by other technologies, in addition to common fiscal uncertainties. This is a fairly low cost, however, when comparing levelized costs and would be encouraging for such an approach. However, it is contradicted somewhat by other studies, including the Electric Reliability Council of Texas's revision of an earlier study, which have put this cost between 19 and 31 percent of the current price per KWh (DOE 2008).

These various plans all have drawbacks and suffer from a great deal of uncertainty. The complexities of both grid physics and economics make it difficult to predict costs and behavior. The important next step for integrating wind and expanding wind penetration is to assess the costs of expanding or modernizing the grid and analyze methods for doing so. DOE's report is a good start and can inform our decisionmaking, but it lacks the specificity required to produce sound policy.

\section{Conclusion}

Continued economic analysis is important not only to answer policy ques- tions involving grid modernization and integration, but also to ensure honest examination of the incentives that will be produced by current and future wind power subsidies. US policy towards wind power has helped displace some traditional methods of power generation by reducing costs for renewable generators and ensuring more electricity comes from clean sources. This is beneficial to those concerned about carbon emissions and likely helped wind become a mature technology. However, maintaining these costly policies may be misguided when it comes to energy independence and grid stability. They have brought inefficiencies into the market and skewed the incentives required to ensure future expansion of wind power by reducing incentives to innovate and explore high-wind areas and encouraging wind farm construction in areas where wind power is inefficient or unneeded. These technologies are fairly mature, and it would likely be more economically efficient to halt subsidies for both wind and other mature technologies (and thereby their unintended consequences). Investments should instead be direct towards research and infrastructure to provide the incentives and the resources this mature technology and developing technologies need to grow in a more efficient manner.

\section{References}

American Wind Energy Association (AWEA). 2013. "Federal Production Tax Credit for Wind Energy" Accessed March 22, 2014. https://www.awea.org/Advocacy/Content.aspx?ItemNumber $=797$.

Burnage, Stephen. 2009. "The US Electric Transmission Grid: Essential National Infrastructure in Need of Comprehensive Legislation.” Accessed May 23, 2013. http://www.renewabletrans.com/Transmission_White.pdf.

Business Council for Sustainable Energy and Bloomberg Finance L.P. 2014. "Sustainable Energy in America 2014 Factbook.” Accessed March 22, 2014. http://www.bcse. org/factbook/pdfs/2014\%20Sustainable\%20Energy\%20in\%20America\%20 Factbook.pdf.

Clipper Windpower. 2008. Clipper Windpower and BP Alternative Energy Form Joint Venture to Develop up to 5,050 MW. Last updated July 30, 2008. http://www. clipperwind.com/pr_073008.html. 
COMPETE. "Competitive Electricity Markets Drive Renewables, Demand Response, Conservation, Efficiency and Innovation”. Accessed November 30, 2013. http:// www.competecoalition.com/resources/competitive-electricity-markets-driverenewables-demand-response-conservation-efficiency-a.

Database of State Incentives for Renewables \& Efficiency (DSIRE). 2013. "Renewable Electricity Production Tax Credit (PTC).” U.S. Department of Energy and the North Carolina Solar Center. Last modified November 02, 2013. http://www. dsireusa.org/incentives/incentive.cfm?Incentive_Code=US13F.

Federal Energy Regulatory Commission. 1996. “Order No. 888.” Accessed November 30, 2013. http://www.ferc.gov/legal/maj-ord-reg/land-docs/rm95-8-oow.txt.

Gray, C. Boyden. 2012. "Why the U.S. Needs a Networked Energy Grid." The Washington Post, October 11, 2012. Accessed March 22, 2014. http://www.washingtonpost.com/opinions/why-the-us-needs-a-networked-energy-grid/2012/10/11/ e2c14c92-13da-11e2-be82-c3411b7680a9_story.html.

GW Solar Institute. 2012. "Energy Incentives: The Power Behind the Power.” The George Washington University. Accessed January 1, 2014. http://solar.gwu.edu/resources/energy-incentives-power-behind-power-o.

Huntowski, Frank, Aaron Patterson and Michael Schnitzer. 2012. "Negative Energy Prices and the Production Tax Credit". Northbridge Group. Accessed December 1, 2013. http://www.nbgroup.com/publications/Negative_Electricity_Prices_ and_the_Production_Tax_Credit.pdf.

Jenevein, Patrick. 2013. "Wind Power Subsidies? No Thanks". The Wall Street Journal, April 1, 2013. Accessed November 30, 2013. http://online.wsj.com/news/articles/SB10001424127887323501004578386501479255158.

Jenkins, Jesse, Mark Muro, Ted Nordhaus, Michael Shellenberger, Letha Tawney, and Alex Trembath. 2012. "Beyond Boom and Bust: Putting Clean Tech on a Path to Subsidy Independence.” The Brookings Institution. Accessed May 2, 2013. http://www. brookings.edu/ /media/Research/Files/Papers/2012/4/18\%20clean\%20investments\%20muro/0418_clean_investments_final\%20paper_PDF.

Lazard. 2013. "Lazard's Levelized Cost of Energy Analysis - Version 7.o.” Accessed March 22, 2014. http://gallery.mailchimp.com/ce17780900c3d223633ecfa59/ files/Lazard_Levelized_Cost_of_Energy_v7.o.1.pdf.

Lerner, Eric J. 2003. "What's Wrong with the Electric Grid?” American Institute of Physics. Accessed May 2, 2013. http://www.aip.org/tip/INPHFA/vol-9/iss-5/ p8.html.

Lopez, Anthony, Billy Roberts, Donna Heimiller, Nate Blair, and Gian Porro. 2012. U.S. Renewable Energy Technical Potentials: A GIS-Based Analysis. National Renewable Energy Laboratory. Accessed May 2, 2013. http://www.nrel.gov/docs/fy120sti/51946.pdf.

Malik, Naureen S., and Julie Johnsson. 2013. "Nuclear Industry Withers in U.S. as Wind Pummels Prices.” Bloomberg, March 3, 2013. Accessed May 2, 2013. http://www. bloomberg.com/news/2013-03-11/nuclear-industry-withers-in-u-s-as-wind-pummels-prices-energy.html.

New York Independent System Operator (NYISO). 2005. "Blackout August 14, 2003 Final Report.” Accessed March 30, 2014. http://www.nyiso.com/public/webdocs/media_room/press_releases/2005/blackout_rpt_final.pdf.

Open Energy Information (OpenEI). 2013. “Transparent Cost Database.” Accessed November 29, 2013. http://en.openei.org/wiki/Transparent_Cost_Database.”

Pfund, Nancy, and Ben Healy. 2011. "What Would Jefferson Do? The Historical Role of Federal Subsidies in Shaping America’s Energy Future.” Accessed March 22, 2014. 
http://www.dblinvestors.com/documents/what-would-Jefferson-do-final-version.pdf.

Porter, Kevin, Sari Fink, Jennifer Rogers, Christina Mudd, Michael Buckley, and Cali Clark. 2012. "PJM Renewable Integration Study." GE Energy. Accessed March 22, 2014. http://www.pjm.com/ /media/committees-groups/task-forces/irtf/ postings/pris-task3b-best-practices-from-other-markets-final-report.ashx.

Public Utility Commission of Texas. 2013. "New Electric Generating Plants in Texas Since 1995.” Accessed March 22, 2014. http://www.puc.texas.gov/industry/ maps/elecmaps/gentable.pdf.

Styles, Geoffrey. 2013. “Wind Energy Tax Credit: Is It Worth the Money?” Christian Science Monitor, December 6, 2013. Accessed March 22, 2014. http://www.csmonitor.com/Environment/Energy-Voices/2013/1206/Wind-energy-tax-creditIs-it-worth-the-money.

U.S. Department of Energy (DOE). 2008. 20\% Wind Energy By 2030: Increasing Wind Energy's Contribution to U.S. Electricity Supply. Energy Efficiency and Renewable Energy. Accessed May 5, 2013. http://www.nrel.gov/docs/fyo8osti/41869.pdf. . 2011. 2011 Wind Technologies Market Report. Energy Efficiency and Renewable Energy. Accessed November 30, 2013. http://www1.eere.energy.gov/wind/ pdfs/2011_wind_technologies_market_report.pdf. . 2013. "Key Federal Legislation.” Alternative Fuels Data Center. Last modified April, 25 2013. http://www.afdc.energy.gov/laws/key_legislation.

U.S. Energy Information Administration (EIA). 2012. “Canada Week: Integrated Electric Grid Improves Reliability for United States, Canada.” Last modified November 27, 2012. http://www.eia.gov/todayinenergy/detail.cfm?id=8930 . 2013. "Levelized Cost of New Generation Resources in the Annual Energy Outlook 2013." Last modified January 28, 2013. http://www.eia.gov/forecasts/aeo/er/ electricity_generation.cfm

. 2014. "Annual Energy Outlook 2014 Early Release Overview.” Accessed March 22, 2014. http://www.eia.gov/forecasts/aeo/er/pdf/o383er(2014).pdf.

Wald, Matthew L. 2008. "Wind Energy Bumps Into Power Grid Limits.” New York Times, August 26, 2008.

Samuel S. Webster is a second year Master of Public Policy student at the George Washington University focusing on energy and technology policy, and specifically on how technology can help produce better public policy impacts and improve the process of policymaking. He earned a BA in classical civilizations from Loyola University Chicago in 2008 and a Post-Baccalaureate in classics from the University of Pennsylvania in 2011 before making the transition into public policy. He currently holds a position as technology and policy support officer for the National Center for Victims of Crime. Upon obtaining his MPP, he hopes to continue working at the intersection of public policy and technology.

The author would like to thank Julian Hoffman and Amit Ronen for all of their time spent making this paper legible, accurate, and maybe even reasonable. The author thought writing a paper in such a quickly changing field would be difficult, but keeping it on track through this process must have been nothing less than heroic. Those efforts and concern for the paper's integrity do not go unappreciated. The author would also like to thank Professor Gerald Brock for the initial opportunity to write this paper, and for his guidance and support, without which this paper would have never been submitted. 